\title{
Routine Medical Checkup Knowledge, Attitude and Practice among Health Care Workers in a Tertiary Health Facility in Calabar, Cross River State, Nigeria
}

\author{
Idang Neji Ojong ${ }^{1}$, Alberta David Nsemo ${ }^{1} \&$ Prudence $\mathrm{Aji}^{2}$ \\ ${ }^{1}$ Department of Nursing Science, College of Medical Sciences, University of Calabar, Cross River State, Nigeria \\ ${ }^{2}$ University of Calabar Teaching Hospital, Calabar, Cross River State, Nigeria \\ Correspondence: Dr Idang Neji Ojong, Department of Nursing Science, University of Calabar, Cross River State, \\ Nigeria. E-mail: idangojong@yahoo.com
}

Received: April 8, 2020 Accepted: May 24, 2020 Online Published: May 29, 2020

doi:10.5539/gjhs.v12n8p27 URL: https://doi.org/10.5539/gjhs.v12n8p27

\begin{abstract}
Introduction: Routine medical checkup is seen as effective in preventing illness and promoting health as well as reducing morbidity and mortality. The aim of this study was to determine the knowledge, attitude and practice of routine health check-up among health care workers (Doctors, Nurses, Radiographers, Lab scientists, Pharmacists, Medical record officers and Health assistants) in a tertiary health facility in Calabar, Nigeria.
\end{abstract}

Methods: A descriptive survey design was adopted for the study. Stratified random sampling technique was used to select sample size of 318. Data was collected through a structured interviewer questionnaire with the reliability coefficient of 0.83. Data generated were analyzed using statistical package for social sciences (SPSS v.20). The significance of the hypothesis was tested using $\mathrm{Chi}$ - Square statistics at $<0.05$ level of significance.

Result: From the findings, majority of the respondents, 295 (92.8\%) had good knowledge of routine health checkup. Most respondents, $205(64.5 \%)$ had positive attitude towards routine health checkup. And a few respondents, $147(46 \%)$ practiced routine health checkup. Hypothesis revealed that the calculated $\mathrm{X}^{2}$ value $\left(5.92^{\mathrm{a}}\right)$ was greater than the critical $\mathrm{X}^{2}$ value of 3.84 at $<0.05$ level of significance showing that there was a significant relationship between Doctors and Nurses knowledge and practice of routine health checkup.

Conclusion: In conclusion, health workers had good knowledge and positive attitude towards routine health checkup. Poor practice of routine medical checkup was also observed. Hence, the researchers recommended that regular seminars and mandatory annual medical examinations should be organized for health workers in all the departments in the hospital to improve their knowledge and practice of routine health check-up. There is need to study the factors associated with practice of medical checkup among Doctors and Nurses in the study area.

Keywords: knowledge, attitude, practice, healthcare workers, routine medical checkup, tertiary facility

\section{Introduction}

Routine medical checkup is a form of preventive measures involving thorough history, physical examination and screening of asymptomatic persons by physicians on a regular basis as part of a routine health care process (WHO 2010).The average life expectancy at birth in Nigeria rose from 46 years in 1990 to 53 years in 2011 with a shift in curative medical to preventive medical practice (United Nations World Population Project 2012). According to the latest World Health Organization, data published in 2018, life expectancy in Nigeria is; male 54.7, female 55.7 and a total life expectancy is 55.2 which gives Nigeria a world life expectancy ranking of 178 (WHO, 2018).

Life expectancy and prosperity have risen in developed and developing countries over the past 50 years and is expected to continue rising by 2020, (Lomborg, 2002). In developing world it is expected to pass age 70 years barrier, hence causing the world's life expectancy to continue to climb. Health was defined by the WHO as the state of physical, mental and social wellbeing, not merely the absence of disease or infirmity (Morby's Medical, Nursing and Allied Health Dictionary, 1990). Periodic or Routine medical checkup is seen as effective in preventing illness and promoting health as well as reducing morbidity and mortality (Damiani, Ferdeco and Basso, 2012). A checkup examination is defined as health care motivated by the need to assess general health and prevent future illness rather than to attend to symptoms (Sox, 2013). Hence, people around the world pay varying levels of 
attention to health issues and give different levels of priority, regarding medical checkup. During this process of routine checkup some of the non-communicable diseases such as hypertension, cancer; cervical, prostate, breast and diabetes mellitus and so on, can be detected and any declining health condition from normal health is noticed and managed in the form of preventive or curative services thereby reducing the mortality associated with them (Moser, Patrick and Beral, 2009).. It is essential to undertake periodic medical examination since these chronic diseases have a heavy socio-economic burden on individuals and accounts for more than $60 \%$ of the overall global burden of diseases (Si-qing, 2009). Thorough medical examination is necessary and its frequency increases in the face of a health problem that necessitates continuing care. Factors that are non-modifiable like age and family history of some diseases determine the checkup or screening one requires. Likewise, the modifiable risk factors like alcohol consumption smoking, unhealthy life style like physical inactivity, unhealthy diet and sedentary lifestyle are all keys in determining the frequency of checkup (WHO, 2012).

Some studies have shown that these risk factors are more among those in low socio-economic class and more vulnerable to cardiovascular disease and diabetes (Lampert, 2010). Generally, in developing countries including Nigeria, where the practice of periodic or routine medical checkup is poor, very few studies have been conducted on it. A study on perception and practice of periodic medical checkup by traders in South East Nigeria, reported that $74.9 \%$ were aware of periodic medical checkup. $61.2 \%$ have their major source of information from friends and $18.2 \%$ from mass media. The study concluded that there is a high level of awareness of periodic medical checkup, but low practice level among the group (Eke, Eke, Joe-Ikechebelu, \& Okoye 2012).Also another study on periodic medical checkup, knowledge and practice in a community in South West Nigerian showed that $62 \%$ have heard of periodic medical checkup $79 \%$ of those who heard have done it and $48.2 \%$ of those who have done it had frequent medical checkup. 50\% had general medical examination, $32.2 \%$ blood pressure check, $6.9 \%$ visual check, $6.2 \%$ dental check and $4.6 \%$ blood sugar check. $67.6 \%$ had medical checkup every six months $9.6 \%$ yearly and $8.1 \%$ every two years. (Ilesanmi, Omotoso, Alele, \& Amenkhienan, 2015).

A review of literature in the area of study showed that routine health checkup did not yield much and no adequate information, no differentiation in data of staff who came for routine health checks and for consultation due to ailments were seen.The need for medical checkup cannot be over emphasized, and everybody is expected to get checkup as they age as it gives a good picture of their health status; hence this study is carried out to determine the knowledge, attitude and practice of routine health checkup by health workers in tertiary health Facility in Calabar Metropolis, Cross River State, Nigeria. .

\subsection{Research Questions}

* What is the level of knowledge of routine health checkup among health workers (Doctors, Nurses, Radiographers, Lab scientists, Pharmacists, Medical record officers and Health assistants) in tertiary health facility in Calabar?

* What is the attitude towards utilizing routine health checkup among health workers (Doctors, Nurses, Radiographers, Lab scientists, Pharmacists, Medical record officers and Health assistants) in tertiary health facility in Calabar?

* Does health workers (Doctors, Nurses, Radiographers, Lab scientists, Pharmacists, Medical record officers and Health assistants) in tertiary health facility in Calabar practice routine medical checkup?

\subsection{Hypothesis}

There is no significant relationship between Doctors and Nurses knowledge and practice of routine medical checkup in tertiary health facility in Calabar

\subsection{Significance of Study}

The findings from this study will help in educating health workers on the risk of not having a routine health checkup and how to prevent such through adopting positive life style steps towards medical checkups. The findings if disseminated will help in creating specific health programs and intervention aimed at improving the preventing health behaviors and quality of life of health workers in the study area

\section{Literature Review}

\subsection{Knowledge of Routine Health Checkup}

Eke, et al. (2012) in their study on periodic health examination, revealed that about $74.9 \%$ were aware of periodic medical checkup; all females and $67.9 \%$ of males. Major source of information was through friends $(61.2 \%)$, then mass media (18.2\%). The commonest known type of medical checkup was general examination $(60.7 \%)$, then blood pressure measurement (55.4\%). Also Umuerri and Aiwuyo (2020) study in Delta State discovered high 
prevalence rate of blood pressure, good knowledge of medical checkup but poor practice of checkup among respondents in the study area, same was supported by (WHO, 2019).Furthermore, Olayinka, Omotoso and Ibidun (2015) on knowledge of medical check-up among respondents in South- West Nigeria revealed that among the 144 who have heard of medical check-up, 68 (47.2\%) felt it should be done when one is healthy. Half of those who responded to questions on types of medical check-up $65(50 \%)$, knew general examination as a form of medical check-up. Only $6(4.6 \%)$ knew blood sugar could be done as a form of routine check-up. Concerning frequency of medical check-up 92 (67.6\%) felt every 6 monthly medical check-up was ideal. Overall, 114 (79.2\%) of those who were aware of periodic medical check-up had ever had it done. In the same vein, Tahira, Muhammad and Shahzad (2017) in their study revealed that overall $63 \%$ of the students, both from medical and non-medical institutions, had awareness about the knowledge and practice of periodic medical examination. Among medical students $68 \%$ and $61 \%$ among non- medical students had knowledge about periodic medical examination. Hoebel, Starker , Jordans, Richter and Lampert (2014) study on determinants of health check attendance in adult, findings from the cross sectional German health update showed that majority of the respondents had good knowledge but practice was poor. In line with the above, Usman, Edet-Utan, Suleiman, Isola, Akantayo and Adu (2016) study on Periodic medical checkup among residents of three Nigerian South-Western State revealed high level of awareness and inadequate practice of periodic health checkup among respondents. This calls for awareness creation on routine health checkup in the study area.

\subsection{Attitude Towards Routine Health Checkup}

With regards to attitude of staff on routine health checkup, Tahira et al (2017), stated that all the respondents were aware of a routine medical check-up; however, $26.7 \%$ of these respondents were aware of an existing program of routine checkups within the hospital attended a medical check-up at least once every year, with a slightly higher proportion among the non-medical staff $(36.3 \%)$. The highest proportion of staff who attended medical check-ups was found to be in the $25-34$ year age group (37.1\%). More females $(95.7 \%)$ than males $(90.7 \%)$ attended medical check-ups. The highest proportion of staff that practiced regular medical check-ups had attained a tertiary level of education. Majority of the respondents both medical $(100 \%)$ and non-medical $(91.2 \%)$, felt that a routine medical check-up was important. A minority of non-medical staff (8.9\%) did not feel it was important. The most important barrier to the practice of routine medical check-ups was the cost, as stated by $72.4 \%$ of the respondents. At par with this result, were findings from Hunt, Adamson, Hewitt and Nazereth (2011), which revealed more women seeking medical care than men on issues relating to back pains and headaches. Health care that is more affordable and accessible is recommended for the respondents in this study area with intensive awareness creation for males on importance of health checkup and health lifestyle.

According to Eke et al. (2012), over $90 \%$ of the respondents had high expectations on the effectiveness of medical checkups on early detection of diseases. The vast majority (92.8\%) of persons aged 15 and above believed that "majority of diseases can be detected earlier through medical checkups" and $94.4 \%$ of the persons and above believed that "for the majority of diseases, detection at earlier stages can improve their prognosis". Furthermore, the majority opined that history taking $(90.5 \%)$ and physical examination $(92.5 \%)$ by doctors were always necessary components of medical checkups. Most of them (94.5\%) preferred the checkup result to be interpreted and explained by a doctor. Tahira et al (2017) in their study revealed that results revealed that $76(28 \%)$ respondents reported internet as their source of information about medical examination, while 60 (22\%) respondents mentioned health workers and $(33 \%)$ of respondents reported ignorance for practicing periodic medical examination. Some others were not practicing because of their busy schedules $(25 \%)$ and cost of investigations (20\%). The result is also supported by (Limm, Flaxman, Daniel, Shibuya and Adair- Rohani, 2010). Education program is recommended to increase their knowledge and importance of medical checkup.

\subsection{Practice of Routine Health Checkup}

Akande, Tanimola and Salaudeen (2004), in their study showed that most of the respondents (82.8\%) had a medical examination since being employed in the hospital. Among those that had pre-employment medical examination done, only $14.1 \%$ had the examination done before assumption of duty. Two-thirds of those who did the medical examination did so just to satisfy the hospital management requirement. Only $20.6 \%$ of the respondents had ever had periodic medical examination (PME) while on employment of the hospital. Among those that ever had PME, the mean number of times that they had periodic medical examination were 2.4. Knowledge of respondents had no significant effect on the practice of PME. It was found that there was a significantly higher level of PME practice among hospital workers who were encouraged to do PME by doctors. This low practice of periodic medical examination did not allow early detection of diseases. Si Si Moss, Sullivan, Newton, and Stocks (2014) study on Effectiveness of general practice - based health checks revealed that general -based health checks 
was higher both on surrogate and final outcomes and the practice was adequate.

In addition, Asuke, Babatunde and Ibrahim (2017) study also revealed that in the private establishment, 47 (42.0\%) have had periodic medical checkups, while $62(44.3 \%)$ in the public establishment have had PME. Of the respondents that have ever undergone PME in the private establishment, 21 (44.7\%) have undergone PME once, while of the respondents in the public establishment, 28 (45.2\%) have undergone PME just once. Majority of the respondents had their last PME 1 year ago, 29 (64.4\%) in private and $26(42.6 \%)$ in public establishments. Concerning feedback, $34(77.3 \%)$ in the private establishment got feedback on PME, while $54(88.5 \%)$ in the public establishment got feedback. In all, 35 (74.5\%) reported improvement in lifestyle as a result of PME in the private establishment and 39 (63.9\%) in the public establishment. Among all of the variables used to assess practice, there was no statistically significant difference between the private and the public establishments. Moreover, Eke et al, (2012) also showed in the study that about $63.8 \%$ feel everybody needs medical checkup. Most (85.5\%) respondents feel medical checkups can improve their work efficiency. Only $29.4 \%$ of males and $39.4 \%$ of females practiced periodic medical checkup. Age, gender and educational status were found not to affect practice of periodic medical checkup significantly. This calls for intensive awareness campaign on affordable and mandatory periodic medical checkup in the study area.

\subsection{Theoretical Framework}

\subsubsection{Theory of Reasoned Action}

The Theory of Reasoned Action (TRA) is a model that finds its origins in the field of social psychology. This model developed by Fishbein and Ajzen (1975) defines the links between beliefs, attitudes, norms, intentions, and behaviors of individuals. According to this model, a person's behavior is determined by its behavioral intention to perform it. This intention is itself determined by the person's attitudes and his subjective norms towards the behavior. Fishbein and Ajzen (1975) define the subjective norms as "the person's perception that most people who are important to him think he should or should not perform the behavior in question" (Fishbein \& Ajzen, 1975).

This theory can be summarized by the following equation:

Behavioral Intention $=$ Attitude + Subjective norms

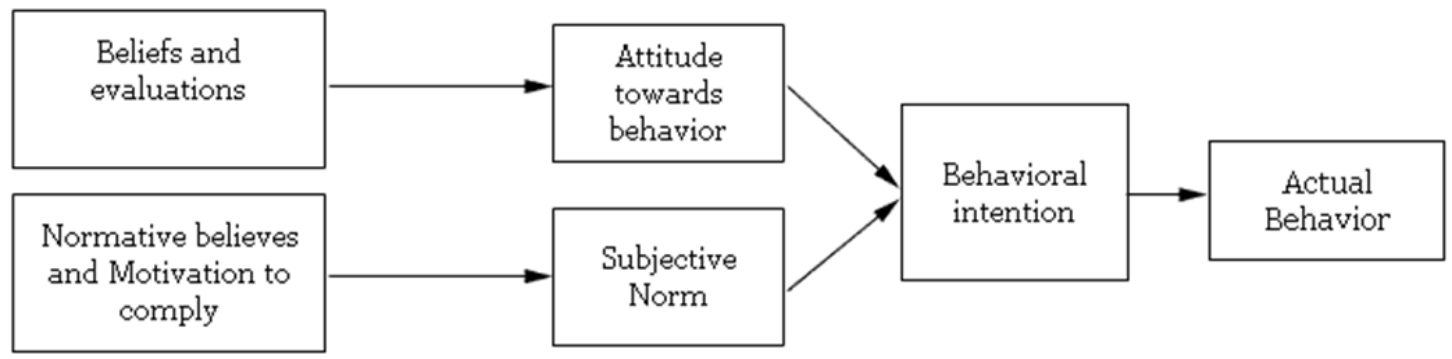

According to TRA, the attitude of a person towards a behavior is determined by his beliefs on the consequences of this behavior, multiplied by his evaluation of these consequences. Beliefs are defined by the person's subjective probability that performing a particular behavior will produce specific results. This model therefore suggests that external stimuli influence attitudes by modifying the structure of the person's beliefs. Moreover, behavioral intention is also determined by the subjective norms that are themselves determined by the normative beliefs of an individual and by his motivation to comply to the norms.

\subsubsection{Application of the Theory to Study}

For a long time, routine health checkup was left to patients, but at the same time health workers were also prone to having illnesses and diseases. This makes Theory of Planned Behavior relevant because of its encouragement of feelings of self-control which would be useful in the case of health care workers going for health checkup. Theory of Planned Behavior is therefore important in understanding the entire process of decision making in either to adopt or not to adopt routine health checkup among health care workers to improve the quality of life of health workers for effective productivity.

\section{Materials and Methods}

\subsection{Research Design}

A descriptive survey research design was adopted for this study. The descriptive survey focuses on the use of questionnaires to obtain information about phenomena of interest with the objective of reporting the manifestation of the events as they occur in the population through sample (Isangedighi, Joshua, Asim \& Ekuri. 2017).This 
design was considered very suitable for this study since the study presented evidence concerning the knowledge, attitude and practice of routine medical checkup using data collection through questionnaires about phenomena playing out in the population.

\subsection{Research Setting}

The setting of this study was tertiary health facility in Calabar metropolis. It was founded in the year 1979. It is a Teaching institution located at the south eastern part of Calabar. It was formally St Margaret hospital in Calabar south but moved to its permanent site on February, 2012. It has the responsibility of manpower development (teaching), treatment of patients at specialist level (clinical services) and promotion of scientific knowledge (research). The hospital is headed by the chief medical director. It's made up of medical doctors, Nurses, pharmacist, medical laboratory scientist, radiographers and medical records department. The new site otherwise called the permanent site is quite a complex structure comprising different units such as the personnel and SERVICOM (where patients report any complaints they have), casualty unit, antenatal clinic, children outpatient department, children emergency department, eye clinic, ear, nose and throat (ENT) clinic, dental clinic, eye ward, department of family health, pharmacy and Nursing administration unit. It is situated behind the college of medical sciences, university of Calabar. The suitability of this area for the study is that despite the fact that the hospital is the only tertiary institution in which the workers are expected to benefit from routine or periodic medical checkup, the researchers observed the reverse during clinical supervision of students as only few afford themselves of these services

\subsection{Target Population}

The target population was1560; this included health workers in all the departments in University of Calabar teaching Hospital: (Doctors 302, Nurses 480, Radiographers 172, Lab scientist 151, Pharmacist 108, medical records officers 107, health assistants 240.

\subsection{Sample and Sampling Technique}

The sample size for this research was calculated by estimating the proportion by use of Taro Yamane's formula for sample size determination. The health workers were proportionately selected from all the departments in the health facility. Therefore, 318 health care workers were used as sample size for the given study

After calculation of the sample size, Stratified sampling technique was used to select health workers in all the departments in the health facility. Each of the seven categories of health care workers was a stratum. The formula $a \mathrm{i}=(\mathrm{Ni} / \mathrm{N}) \mathrm{x}$, was used to determine the number of individuals from each stratum to be included in the study. The number of individuals in each stratum $(\mathrm{Ni})$ was divided into the number of individuals in the population $(\mathrm{N})$ and multiplied by sample size (n), thereafter the size of the stratum (ai) was calculated (Joshua2016). The sample size was distributed as follows: Doctors 46, Nurses 46, Radiographers 45, Lab scientists 45, pharmacists 45, medical record officers 45 and health assistants 46 . A total sample size of 318 was found to be adequate to exhibit the association between variables.

\subsection{Instrument for Data Collection}

A structured interviewer four sections closed ended questionnaire was used. Section A was used to elicit information on Socio demographic data of Respondents. Section B was used to elicit information on knowledge of routine health checkup .Section $\mathrm{C}$ was used to elicit information on attitude towards routine health checkup. Section D was also used in collecting information on practice of routine health checkup. On knowledge questions, respondents who scored between 6-8 points had poor knowledge; those that scored between 9-11 points had good knowledge. On attitude, those respondents that scored between4-9 points had negative attitude, while those that scored between 10-15 points had positive attitude. On practice, scores between13-21 points indicate no practice, while scores between 22-30 points indicate good practices of medical checkup. Face validity of the instrument was ascertained by experts in educational test and measurements and the internal consistency reliability test revealed a Cronbach's alpha value of 0.83 .

\subsection{Method of Data Collection}

Data was collected through face to face administration of questionnaire to the respondents. The administration took a period of two weeks and completed questionnaire retrieved on the spot with the help of a research assistant. Confidentiality of the participants was assured and maintained. Administrative permit was obtained from the health facility and consent was sought from the respondents. The respondents were assured of anonymity and respect of their freedom of choice and that they will not be prejudiced in anyway. Participation was voluntary. 


\subsection{Procedure for Data Analysis}

Data was analyzed using statistical package for social Sciences (SPSS vs. 20) and presented using simple percentages and tables. Chi-square test was used to test the relationship between variables. P- value was set at 0.05 level of significance which implies $95 \%$ level of precision.

\section{Results}

Table 1. Level of knowledge on routine medical checkup among health workers (Doctors Nurses, Radiographers, Lab scientists, Pharmacists, Medical record officers and Health assistants) in tertiary health facility in Calabar ( $\mathrm{n}=$ 318)

\begin{tabular}{lll}
\hline Statements & Yes & No \\
\hline $\begin{array}{l}\text { Health checkup is the process of assessing an individual's state of health so as to } \\
\text { detect, treat and prevent any disease or illness. }\end{array}$ & $318(100 \%)$ & - \\
$\begin{array}{l}\text { Health checkup for health workers reduces the incidence of nosocomial infections } \\
\text { among members of the health team. }\end{array}$ & $146(45.9 \%)$ & $172(54.1 \%)$ \\
Health checkup should be done regularly and not for only one time in life. & $300(94.3 \%)$ & $18(5.7 \%)$ \\
Health workers are supposed to engage in routine health checkup. & $299(94.4 \%)$ & $19(6.0 \%)$ \\
Medical checkups can improve work efficiency of health worker. & $305(95.9 \%)$ & $13(4.1 \%)$ \\
Health checkup brings improvement in the lifestyle of health workers & $145(45.6 \%)$ & $173(54.4 \%)$
\end{tabular}

(Field survey, 2020).

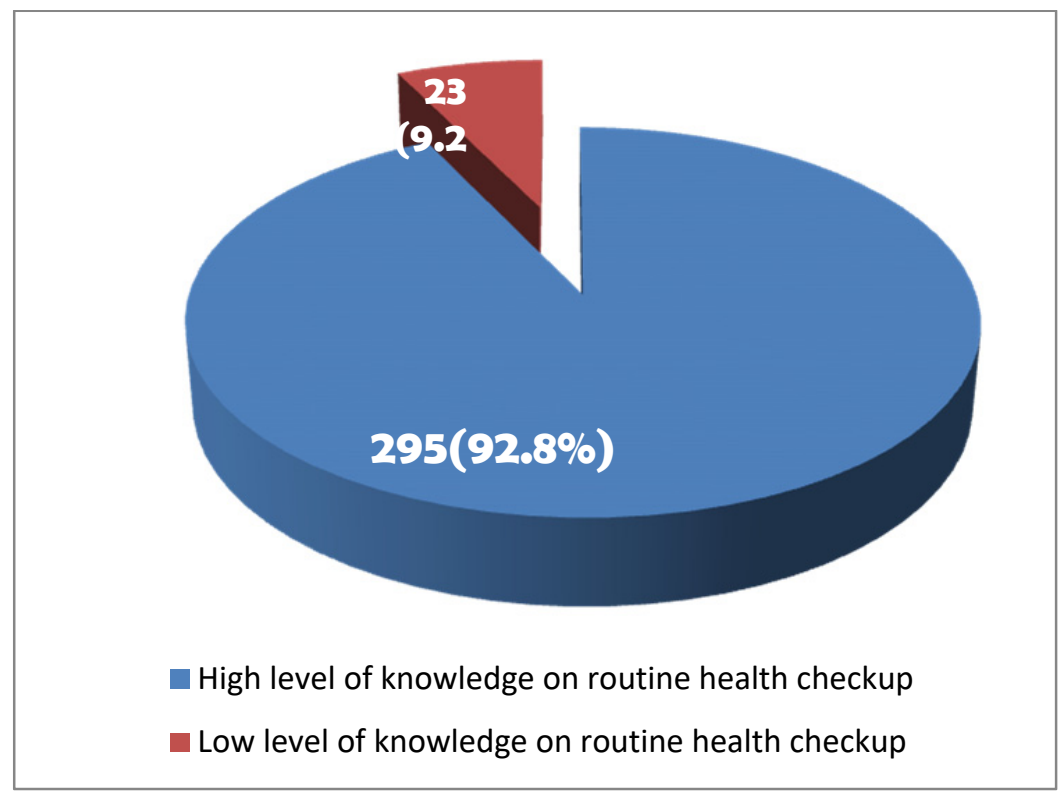

Figure 1. An exploded 3-Dpie chart showing summary of knowledge on routine medical checkup among health workers in tertiary health facility in Calabar

Table 1. All participants, $318(100 \%)$ accepted that health checkup is the process of assessing an individual's state of health so as to detect, treat and prevent any disease or illness. Also, whether 'health checkup for health workers reduces the incidence of nosocomial infections among members of the health team', 146(45.9\%) said 'yes' while $172(54.1 \%)$ said 'no'. On if 'health checkup should be done regularly and not for only one time in life' 300(94.3\%) accepted this statement while 18(5.7\%) did not accept. Two hundred and ninety-nine, representing $94.4 \%$ accepted that health workers are supposed to engage in routine health checkup and 19(6.0\%) did not accept. Regarding medical checkups improving work efficiency of health workers, 305(95.9\%) said 'yes' while 13(4.1\%) said 'no'. Furthermore, on the statement 'health checkup brings improvement in the lifestyle of health workers' $145(45.6 \%)$ 
said; yes' while 173(54.4\%) Therefore, 295(92.8\%) had high level of knowledge and only 23(7.2\%) had low level of knowledge on routine health checkup. This information is presented in figure1 above.

Table 2. Attitude of Health workers (Doctors, Nurses, Radiographers, Lab scientists, Pharmacists, Medical record officers and Health assistants) towards routine medical checkup in a Tertiary health facility in Calabar

\begin{tabular}{lllll}
\hline Statements & SA & A & D & SD \\
\hline $\begin{array}{l}\text { I am always willing to attend routine health } \\
\text { examination because it is necessary and beneficial }\end{array}$ & $211(66.4 \%)$ & $107(3.6 \%)$ & - & - \\
$\begin{array}{l}\text { I like to key into existing programme of routine } \\
\text { check-ups within the hospital }\end{array}$ & $7(2.2 \%)$ & $9(2.8 \%)$ & $189(59.4 \%)$ & $113(35.5 \%)$ \\
$\begin{array}{l}\text { High cost of health check-up makes many health } \\
\text { professionals shy away from checking their health }\end{array}$ & $103(32.4 \%)$ & $51(16.0 \%)$ & $161(50.6 \%)$ & $3(0.9 \%)$ \\
$\begin{array}{l}\text { status regularly } \\
\begin{array}{l}\text { Patients and clients who visit the hospital benefit } \\
\text { more from routine health examination. }\end{array}\end{array}$ & $149(46.5 \%)$ & $151(47.5 \%)$ & $10(3.1 \%)$ & $9(2.8 \%)$ \\
\hline
\end{tabular}

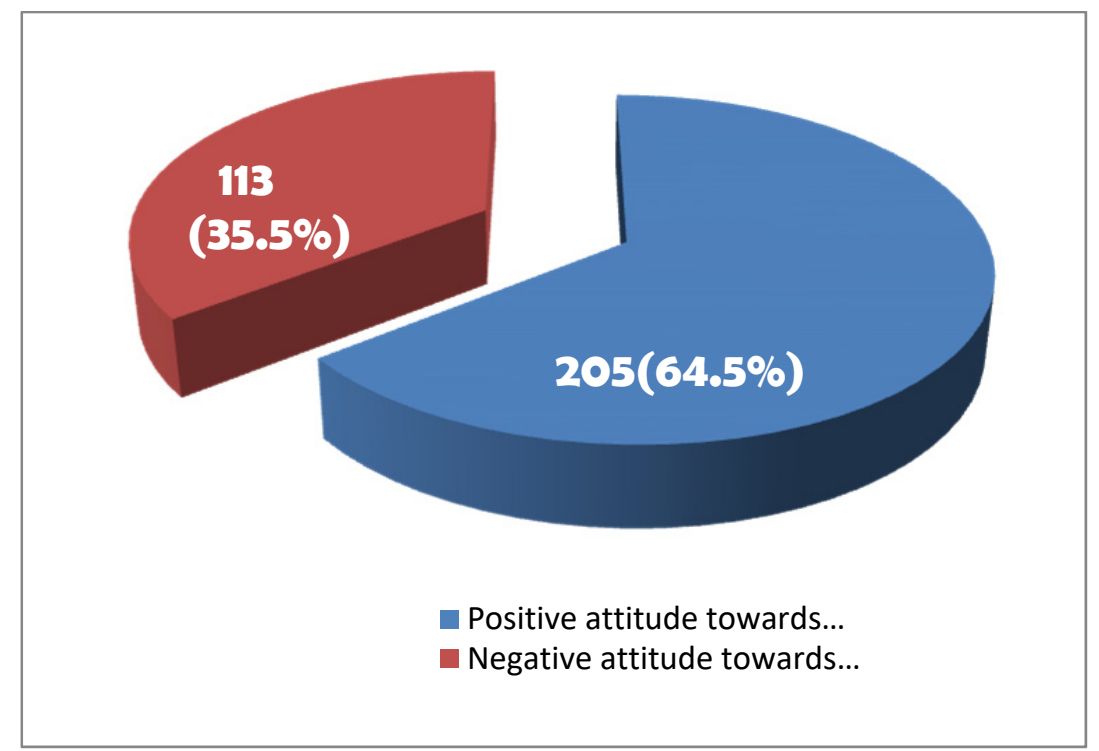

Figure 2. An exploded 3-D pie chart showing summary of health workers attitude towards routine medical checkup in a tertiary health facility in Calabar

Table 2 Out of 318 study participants, two hundred and eleven, representing 66.4 percent strongly agreed that they are always willing to attend routine health examination because it is necessary and beneficial; 107(3.6\%) agreed while none disagreed and strongly disagreed to the statement. On whether participant would like to key into existing program of routine checkup within the hospital, only $7(2.2 \%)$ strongly agreed, $9(2.8 \%)$ agreed, $189(59.4 \%)$ disagreed and $113(35.5 \%)$ strongly disagreed. As regards high cost of health check-up making many health professionals to shy away from checking their health status regularly, 103(32.4\%) strongly agreed, 57(16.0\%) agreed, 161(50.6\%) disagreed while 3(0.95\%) strongly disagreed. Also, 149(46.5\%), 151(47.5\%), 10(3.1\%) and $9(2.8 \%)$ strongly agreed, agreed, disagreed and strongly disagreed to the statement 'patients and clients who visit the hospital benefit more from routine health examination' The final score for attitude of health workers towards routine health checkup was obtained by adding up participants' scores on all items in section C. As a result, $205(64.5 \%)$ had positive attitude while $113(35.5 \%)$ had negative attitude towards routine health checkup. This summary is presented in Figure 2. 
Table 3. Practice of medical checkup among health workers (Doctors, Nurses, Radiographers, Lab scientists, Pharmacists, Medical record officers and Health assistants) in Tertiary health facility in Calabar ( $\mathrm{n}=318$ )

\begin{tabular}{|c|c|c|c|c|}
\hline Statements & Always & Often & Occasionally & Never \\
\hline $\begin{array}{l}\text { Routine health check-up is practiced among members of my area of } \\
\text { specialisation. }\end{array}$ & $\begin{array}{l}8 \\
(2.5 \%)\end{array}$ & $\begin{array}{l}3 \\
(0.9 \%)\end{array}$ & $\begin{array}{l}303 \\
(95.3 \%)\end{array}$ & $\begin{array}{l}4 \\
(1.3 \%)\end{array}$ \\
\hline $\begin{array}{l}\text { How often do you engage in health check-up to maintain a good health } \\
\text { status? }\end{array}$ & $\begin{array}{l}11 \\
(3.5 \%)\end{array}$ & $\begin{array}{l}35 \\
(11.0 \%)\end{array}$ & $\begin{array}{l}272 \\
(85.5 \%)\end{array}$ & - \\
\hline I have had a health check-up within the past year. & $\begin{array}{l}9 \\
(2.8 \%)\end{array}$ & $\begin{array}{l}14 \\
(4.4 \%)\end{array}$ & $\begin{array}{l}120 \\
(37.7 \%)\end{array}$ & $\begin{array}{l}175 \\
(55.0 \%)\end{array}$ \\
\hline I have had check-up for hypertension & $\begin{array}{l}3 \\
(0.9 \%)\end{array}$ & $\begin{array}{l}21 \\
(6.6 \%)\end{array}$ & $\begin{array}{l}171 \\
(53.8 \%)\end{array}$ & $\begin{array}{l}123 \\
(38.7 \%)\end{array}$ \\
\hline I have had check-up for blood sugar level & $\begin{array}{l}3 \\
(0.9 \%)\end{array}$ & 7 & $\begin{array}{l}211 \\
(66.4 \%)\end{array}$ & $\begin{array}{l}97 \\
(30.5 \%)\end{array}$ \\
\hline
\end{tabular}

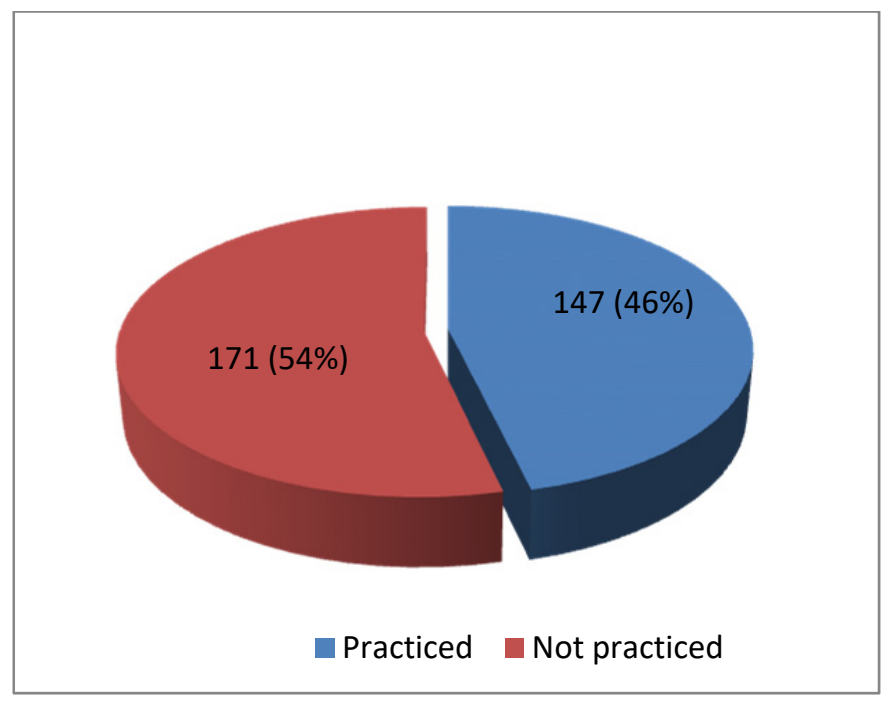

figure 3. An exploded 3-D pie chart showing summary of health worker's practice of routine

Medical checkup in a tertiary health facility in Calabar $(n=318)$.

Table 3 Out of the 318 health workers that participated in the study, $8(2.5 \%), 3(0.9 \%), 303(95.3 \%)$ and $4(1.3 \%)$ accepted that routine health checkup is practice among members of their area of specialization, always, often, occasionally and never respectively. On how often they engage in health checkup to maintain a good health status, $11(3.5 \%)$ said 'always', $35(11.0 \%)$ often, $272(85.5 \%)$ said 'occasionally' while no participant accepted that he/she never engaged in routine health checkup. Nine participants, representing 2.8 percent accepted that they have always had a health checkup within the past year, 14(4.4\%), 120(37.7\%), 175(55.0\%) had it often, occasionally and never respectively. About having had checkup for hypertension, only $3(0.9 \%)$ said always, $21(6.6 \%)$ often, $171(53.8 \%)$ occasionally and $123(38.7 \%)$ never. Also, on having checkup for blood sugar level, 3(0.9\%) responded 'always', 7(2.2\%) said 'often', 211(66.4\%) said occasionally while 97(30.5\%) said never. Regarding the statement, 'I have done breast cancer screening', 6(1.9\%) said they did it always, 55(17.3\%) often, 97(30.5\%) occasionally while $160(50.3 \%)$ said they never had breast cancer screening. On having screened for cervical cancer, no participant accepted that they did it always and often, 19(6.0\%) said occasionally and $299(94.0 \%)$ said 'never'. Additionally, concerning screening for prostate cancer, no participant also said always/often, only $2(0.6 \%)$ accepted occasionally while 316(99.4\%) said they have never had prostate cancer screening. Participant's responses in this section were scored and the sum of scores was determined to compute the final score for health 
workers practice of routine checkup. yj147 (6.2\%) practice, while $171(53.8 \%)$ did not practice. This summary is indicated in FIG 3.

Table 4. Chi-Square Analysis of Association between Doctors and Nurses Knowledge and Practice of Routine Medical Checkup

\begin{tabular}{|c|c|c|c|c|c|c|c|}
\hline \multirow{2}{*}{ Group } & \multirow{2}{*}{ Level of Knowledge } & \multicolumn{2}{|l|}{ Practice of Checkup } & \multirow{2}{*}{ Total } & \multirow{2}{*}{ Df } & \multirow{2}{*}{$\begin{array}{l}\text { Cal } \\
X^{2}\end{array}$} & \multirow{2}{*}{$\begin{array}{l}\text { Crit } \\
\mathbf{X}^{2}\end{array}$} \\
\hline & & Adequate practice & Inadequate Practice & & & & \\
\hline \multirow[t]{2}{*}{ Doctors } & Poor knowledge & $6(5.4)$ & $2(2.6)$ & 8 & & & \\
\hline & Good knowledge & $30(25.6)$ & $8(12.4)$ & 38 & 1 & 5.92 & 3.841 \\
\hline \multirow[t]{2}{*}{ Nurses } & Poor knowledge & $6(6.7)$ & $4(3.3)$ & 10 & & & \\
\hline & Good knowledge & $20(24.3)$ & $16(11.7)$ & 36 & & & \\
\hline Total & & 62 & 30 & 92 & & & \\
\hline
\end{tabular}

*significant at $(\mathrm{p}<.05) ; \mathrm{df}=1 ;$ critical $\mathrm{X}^{2}=3.84$.

Thus, result in table 4 reveals that, the calculated $X^{2}$ value of 5.92 was greater than the critical $X^{2}$ value of 3.84 at $<0.05$ level of significance and 1 degree of freedom. Thus, the null hypothesis was rejected. This means that there was a significant association between Doctors and Nurses knowledge and practice of routine health checkup.

\section{Discussion of Finding}

The findings of research question 1 revealed that majority of the respondents had high level of knowledge of routine health checkup. The findings were in line with Tahira, et. al (2017) in their study which revealed that majority of the students, both from medical and non-medical institutions, had awareness about the knowledge and practice of periodic medical examination. The study also relates with Olayinka, et al. (2015) whose findings revealed good knowledge on periodic checkup but majority of the respondents agreed that 6 monthly medical check-ups is ideal. Overall, majority of those who were aware of periodic medical check-up had ever had it done. Usman, et al. (2016) findings also is in line with the above result. The high level of knowledge exhibited by the health workers in this study could be due to the fact that majority of them are highly educated and are exposed to seminars on routine health checkup and have knowledge on the subject matter. Continuous sensitization is advocated to strengthen their knowledge. Findings from table 2 showed that majority of the respondents had positive attitude towards routine health checkup. The finding of the study is supported by Eke, et al. (2012), which showed that almost all, of the respondents had high expectations on the effectiveness of medical checkups on early detection of diseases. However, the present result of the study does not agree with Tahira et al. (2017), which revealed that only few of these respondents were aware of an existing program of routine check-ups within the hospital. Almost all respondents attended a medical check-up at least once every year, with a slightly higher proportion among the non-medical staff. This reaction of the respondents towards medical checkup could be due to low morale of workers due to unsatisfactory working conditions among others. More effort will thus be required to achieve more qualitative and better health care delivery.

Result of the study on research question three revealed that majority of the staff had not practiced routine health checkup. This finding is in tandem with Eke et al. (2012) who showed in their study that only few of males and females practice periodic medical checkup. Age, gender and educational status were found not to affect practice of periodic medical checkup significantly. The finding was supported by (Si Si Moss et al., 2014). On the other hand, the result of the present study is not in agreement with Akande, et al. (2004), in a study which revealed that most of the respondents had a medical examination since being employed in the hospital. Among those that had pre-employment medical examination done only few had the examination done before assumption of duty. Two-thirds of those who did the medical examination did so just to satisfy the hospital management requirement. Only few of the respondents had ever had periodic medical examination, while on employment of the hospital. The hypothesis result revealed that, the calculated $\mathrm{X}^{2}$ value was greater than the critical $\mathrm{X}^{2}$ value at $<0.05$ level of significance and 1 degree of freedom. Thus, the null hypothesis was rejected. This means that there was a significant association between Doctors and Nurses knowledge and practice of routine health checkup. The result is not in agreement with Akande et al. (2004), in their study which showed that Knowledge of respondents had no significant effect on the practice of Periodic medical examination. Most of the respondents had a medical examination since being employed in the hospital. It was found that there was a significantly higher level of PME practice among hospital workers who were encouraged to do PME by doctors. Eke et al. (2012) is in line with the 
findings of this study as there was a relationship between knowledge and practice of periodic medical checkups. The low practice of periodic medical checkup in this study will not allow early detection of diseases. The study also shows high level of knowledge of routine medical checkup though the actual practice was poor by the nurses, this is contrary to what is expected, that health seeking behavior should have been higher among them due to their knowledge level and their place of work. The findings revealed that the practice of routine medical checkup was not affected by high level of knowledge. The Doctors were more knowledgeable about the subject matter this may be due to their exposure and experience from their schools of taught. Education targeted at improving uptake of routine medical checkup should therefore not be restricted in this study area particular group, it should be disseminated among the Doctors, Nurses, Radiographers, Lab scientists, Pharmacists, Medical record officers and Health assistants. Also intensify effort on seminars and workshops and better health information to the entire populace on routine health checkups should be carried out as there is high level of knowledge on routine medical checkup but poor practice. This will promote the practice of medical checkup among health workers in all the departments in the study area.

\section{Study Implication}

According to the findings of this study, it becomes imperative that health workers in the study area should take routine medical checkup more seriously with the aim of detecting early signs of various disease conditions which in turn, makes them fit for their daily duties.

Also, it is necessary for seminars to be organized with the sole aim of educating health workers in all the departments in the hospital on the importance and types of routine health checkup that will be beneficial to them.

\section{Conclusion}

Based on the result of the study, it can be deduced that Health care workers in the study area have good knowledge of routine health checkup but poor practice.It also reveals that they have positive attitude towards routine examination. Sensitization and Mandatory continued education programs and annual medical examination should be conducted for health care workers in all departments in the study area to improve their knowledge, attitude and practice on routine medical checkups. The result of the study covers only 318 health care workers and cannot be generalized on the entire population. Further study using a larger sample size is recommended. Also, a study should be conducted on factors associated with routine health checkup among Doctors and Nurses in the study area.

\section{Competing Interests Statement}

Authors declare no conflict of interest and no funding was received for this study.

\section{References}

Akande, T. M., \& Salaudeen, A. G. (2004). Practice of Periodic Medical Examination among Hospital Workers in a Nigeria Teaching Hospital. Nigerian quarterly journal of hospital medicine, 14(3) 206-210. https://doi.org/10.4314/nqjhm.v14i3.12722

Asuke, S., Babatunde, J. M., \& Ibrahim M. S. (2017). A Comparative Analysis of the Awareness and Practice of Periodic Health Examination among Workers of Public and Private Establishments in Zaria, North Western Nigeria. Arch Med Surgical, 2(2), 38-42. https://doi.org/10.4103/archms.archms_50_17

Damiani, G., Federico, B., Basso, D. et al. (2012). Socio-economic Disparities in the Uptake of Breast and Cervical Cancer Screening in Italy; A Cross Sectional Study. BCM Public Health, 12, 99. https://doi.org/10.1186/1471-2458-12-99

Eke, C. O, Eke N. O, Joe-Ikechebelu, N. N., \& Okoye, S. C. (2012). Perception and Practice of Periodic Medical Checkup by Traders in South East Nigeria. Afrimedic Journal, 3(2), 24-29.

Fishbein, M., \& Ajzen, I. (1975). Belief, Attitude Intention and Behavior: An Introduction to Theory and Research Reading. MA Addison - Wesley.

Hunt, K., Adamson, J., Hewitt, C., \& Nazereth, I. (2010). Do Women Consult More Than Men?. A Review of Gender and Consultation for Back pain and Headaches. Journal of Semi Research and Policy, 16(2), 108-117. https://doi.org/10.1258/jhsrp.2010.009131

Hoebel, J., Starker, A., Jordan, S., Richter, M., \& Lampert, T. (2014). Determinants of Health Check Attendance in Adults: Findings from the Cross-Sectional German Health Update (GEDA) Study. BMC PublicHealth 14(913). https://doi.org/10.1186/1471-2458-14-913

Ilesanmi, O. S., Omotoso, B., Alele F. O., \& Amenkhienan, I. (2015). Periodic Medical Checkup; knowledge and 
Practice in a Community in South West Nigeria. International Journal of Public Health Research, 5(1), 576-583.

Isangedighi, A. J., Joshua, M. T., Asim, A. E., \& Ekuri, E. E., (2017). Fundamentals of Research and Statistics in Education and Social Sciences. Calabar: University of Calabar, 92.

Joshua, M. T. (2016). Fundamentals of Test and Measurement in Education. Calabar: University of Calabar Press, 64.

Lampert, T. (2010). Smoking, Physical Inactivity and Obesity; Associations with Social Status. Deutsches Arzteblat. Int, 107(1-2), 1-7. https://doi.org/10.3238/arztebl.2010.0001

Limm, S. S., Vos, T., Flaxman, A. D., Daniel, G., Shibuya, K., \& Adair-Rohani, H. (2010). A Comparative Risk Assessment of Burden of Diseases and Injury attributable to 67 Risk Factors and Risk Factor Clusters in 21 Regions 1990-2010: A Systematic Analysis for the Global Burden of Disease Study 2010. The Lancet, 380(9859), 2224-2260. http//doi.org/10.1016/S0140-6736 (12) 61766-8

Lomborg, B. (2002). How healthy is the world? British Medical Journal, 325(7378), 1461-1466. https://doi.org/10.1136/bmj.325.7378.1461

Mosby's Medical, Nursing and Allied Health Dictionary (3rd Ed., 190, 235). CV Mosby company.

Moser, K., Patrick, J., \& Beral, V. (2009). Inequalities in reported use of breast and cervical screening in Great Britain; British Medical Journal, 338, 2025. https://doi.org/10.1136/bmj.b2025

Olayinka S. I., B. Omotoso, F. A., \& Ibidun, A. (2015). Periodic Medical Checkup: Knowledge and Practice in a Community in South West Nigeria. International Journal of Public Health Research, 5(1), 576-583.

Si-quing, L. (2009). Importance of Regular Physical Examination for Early Prevention and Treatment of Disease in Middle age and Elderly People. Chinj, Convalescent Medicine, 14(5), 429-430.

Si Si Moss, J.R., Sullivan, T. R. Newton, S. S., \& Stocks, N. P., (2014). Effectiveness of General Practice-based Health Checks; A Sytematic Review and Meta-analysis. British Journal of General Practice, 64(618), e47-e53. https://doi.org/10.3399/bjgp14X676456

Sox, H. C. (2013). The Health Checkup, was it effective? Could it be effective? JAMA, 309, 2496- 497. https://doi.org/10.1001/jama.2013.5040

Tahira, S., Muhammad, A. \& Shahzad, A. A. (2017). Awareness among Medical and Non-Medical Students About the Practice of Periodic Medical Examination. JIIMC, 12(2), 116-119

Umuerri, E. M., \& Aiwuyo H. O. (2020). Prevalence and Correlates of Prehypertension and Hypertension Among Adults in Delta State Nigeria: A Cross Sectional Community Based Study. Ghana MedicalJournal, 54(1), 48-57. http://doi.org/10.4314gmjv54i1.8.

United Nation World Population Prospect. (2012). Revision cited 2014 Dec. esa.unorg/wpp2012_\%20 KEY\% 20FINDINGS.pdf

Usman, S. O., Edet-Utan, O., Suleiman, A., Isola, I. N., Ojogbede, A., Akintayo-USMAN, N. O., ,.. \& Adu, A.S. (2016) Periodic Medical Check-Up Amont Three Nigerian South-Western States. Journal of Contemporary Medicine, 6(3), 174-182. https://doi.org/10.16899/ctd.65941

World Health Organisation. (2002). Innovative Care for Chronic Conditions; Building blocks for action. Geneva, Switzerland; WHO2002

World Health Health Organisation. (2010). Towards a strategy for Cancer Control in the Eastern Mediterranean Region.1st Ed. Cairo, World Health OrganisationRegional office for the Mideterranean, 2010.

World Health Organisation. (2018). Global Data on life Expectancy in Nigeria. https://www.vanguardngr.com

World Health Organisation. (2019).Global Health Observation (GHO) Data: Raised Blood Pressure. Retrieved from: http://www.who.int/gho/ncd/risk factors/blood pressure prevalence text/en/ (Accessed on 08/03/2019).

\section{Copyrights}

Copyright for this article is retained by the author(s), with first publication rights granted to the journal.

This is an open-access article distributed under the terms and conditions of the Creative Commons Attribution license (http://creativecommons.org/licenses/by/4.0/). 